\title{
Adult learners' retention of collocations from exposure
}

\author{
Philip Durrant Bilkent University, Ankara and \\ Norbert Schmitt University of Nottingham
}

Received March 2008; revised July 2008; accepted September 2008

\begin{abstract}
Formulaic language is widely recognized to be of central importance to fluent and idiomatic language use. However, the mechanics of how formulaic language is acquired are not well understood. Some researchers (e.g. Nick Ellis) believe that the chunking inherent in formulaic language drives the language learning process. Others (e.g. Wray) claim that adult second language learners take an essentially non-formulaic approach to language learning, analysing their input into individual words and not retaining information about what words appear together. If the second model is right, it represents a crucial difference between child first and adult second language learning. This 'non-formulaic' model is tested here through a lab-based study of collocation learning. Our findings indicate that, contrary to the model, adult second language learners do retain information about what words appear together in their input. This suggests that any shortfall in non-natives' knowledge of collocational associations between words is due to inadequate input, rather than a non-nativelike approach to learning. The study also examines the effects of different forms of repetition on collocation acquisition and draws conclusions regarding pedagogical activities for learning.
\end{abstract}

Keywords: collocation learning, formulaic language, chunking, usage-based models, second language acquisition

\section{Introduction}

Recent years have seen much interest amongst language teachers and researchers in the role played by formulaic sequences in fluent and

Address for correspondence: Philip Durrant, Graduate School of Education, Bilkent University, 06800 Ankara, Turkey; email: durrant.phil@googlemail.com 
idiomatic language use (Lewis, 2000; Nattinger and DeCarrico, 1992; Wray, 2002; Biber et al., 2004; Schmitt, 2004; Hoey, 2005). It is becoming increasingly clear that our models of language acquisition (and our attendant approaches to teaching) need to provide an accurate description of how formulas fit into the learning process, both because mastery of such formulas is held to be important in attaining a fluent and idiomatic control of the language, and because it has been suggested that the processes involved in formula learning may be central to language learning in general (Ellis, 2001). In spite of the importance of this area, however, empirical evidence remains sparse.

The phenomenon of frequent collocation between pairs of words holds a central place in the scheme of formulaic language research and offers an excellent testing ground for models of formula acquisition. As defined within the 'neo-Firthian' tradition represented by corpus linguists such as Sinclair (1991), Stubbs (1995) and Hoey (2005), collocations are words that appear together more frequently than their individual frequencies would lead us to expect (Jones and Sinclair, 1974; Hoey, 1991). Collocating words 'predict' each other, in the sense that, where we to find one part of a collocating pair, the chances of finding the other increase. Although Firth (1968) originally conceived of collocation as a purely textual phenomenon, researchers in this tradition have since given the notion a psychological interpretation, seeing the frequent co-occurrence of words as evidencing the existence of 'semipreconstructed phrases that constitute single choices' for the speaker (Sinclair, 1987: 320), linguistic 'chunking' (Ellis, 2003) or 'a psychological association between words' (Hoey, 2005: 5).

In this view, high-frequency collocations can be seen as one type of 'formulaic sequence' or 'construction'. 'Formulaic sequence' is defined by Wray (2002: 9) as 'a sequence, continuous or discontinuous of words or other elements which is ... stored and retrieved whole from memory at the time of use, rather than being subject to generation or analysis by the language grammar'. 'Construction' is defined by Goldberg (2006: 5) as linguistic items that are independently represented in the language system, either because they are not predictable on the basis of other knowledge or because they are sufficiently frequent for their independent storage in long-term memory to be cognitively efficient. These terms also fit Palmer's (1933: 4) earlier and more-pedagogicallyoriented definition of collocations as 'successions of words [that] must or should be learnt ... as an integral whole or independent entity, rather than by the process of piecing together their component parts'. 
Collocation is a particularly useful type of formulaic language for researchers to study:

- because it is pervasive;

- because a number of quantitative methods have been developed for its study (see, e.g., Manning and Schütze, 1999: Chapter 5);

- because - unlike longer strings and obviously idiomatic expressions - it is often relatively lacking in salience in the input, so is likely to be subject to more implicit processes of acquisition than other - perhaps consciously taught - sequences; and

- because a treatment of collocation can be easily extended to a wider range of formulaic language (as shown in, for example, the treatments by Sinclair, 2004; Hoey, 2005).

\section{Acquisition of collocations}

Ellis (2001) describes one model of collocation learning in a first language (L1). He conceptualizes collocation as the product of a psychological mechanism know as 'chunking'. The notion of chunking was introduced by Miller (1956) to explain why the span of human short-term memory remains at a more-or-less constant seven items, regardless of the amount of information encoded by each item. Miller argued that the capacity of short-term memory is not tied to the amount of information in a message, but to the number of 'chunks' of information. By recoding more simple items (such as phonemes) into more complex chunks (such as words), we can massively increase the amount of information our memory can handle. Ellis suggests that the same process lies behind collocation learning: two or more words which frequently co-occur are recoded as a chunk and henceforth treated as a single entity. This process is recursive, with chunks themselves subsequently available for combination into still larger units, enabling language users to encode progressively greater amounts of information in short-term memory, so increasing the efficiency (and therefore the fluency) of communication (Ellis, 2001: 38-40).

This chunking process is driven, Ellis claims, by a principle of associative learning, which he calls the 'law of contiguity'. This rule states that, '[o]bjects once experienced together tend to become associated in the imagination, so that when any one of them is thought of, the others are likely to be thought of also' (James, 1890, quoted in Ellis, 2001: 42). Under the influence of this law, the frequent co-occurrence 
of two words in linguistic input (and hence in short-term memory) will lead to their becoming associated in long-term memory, and consolidated into 'chunks'. In this way, long-term memory becomes tuned to frequent collocations, such that when the same items are encountered in subsequent input they will be perceived as units. Short-term memory for language including such sequences will therefore be greater than that for less formulaic language (2001: 41).

The chunking of frequently co-occurring forms proceeds, Ellis maintains, through implicit processes, i.e. without the learner's conscious attention. It provides speakers with a vast amount of knowledge about the transition probabilities of sequences in their language. This is knowledge of which they may not be consciously aware, but which is evident in their performance in language use and in psycholinguistic experiments (Ellis, 2002). However, Ellis is careful to point out that, while such processes constitute a large part of collocation learning, there is more to collocation than purely formal associations and more to chunking than implicit learning. Meaning also plays an important role. Sound sequences that are regularly associated with a useful communicative function will be more salient to the learner, and so are more likely to be learnt than those that are not (2001: 41). Whereas the formation of formal associations merely requires the learner to match sound with sound (in more technical terms, to create links within a single cognitive 'modality'), the mapping of form to function requires that sound be matched with other aspects of experience (they must establish 'crossmodal' links). Forming such links requires, Ellis (2005) claims, a conscious focus of attention. Consciousness both brings together the input of different cognitive modalities and provides the necessary conceptual structuring to determine what aspect of a particular experience a sound is referring to. Whereas implicit association formation is a slow cumulative process, following a power law of practice, conscious learning can be instantaneous. This is one reason why knowledge of collocation is not entirely determined by input frequencies (Ellis and Larsen-Freeman, 2006). Once an association is consciously made, however, the resultant chunk is itself subject to implicit tallying processes and so open to frequency effects (Ellis, 2005).

Whether the processes of collocation learning described by Ellis apply also to adults learning a second language (L2) remains an open question. While acknowledging both important differences between child L1 and adult L2 learners and a lack of empirical research on the subject, 
Ellis suggests that similar mechanisms may be at work (2003: 72-74). However, others have argued against this position. Perhaps the clearest statement of the opposing view comes from Wray (2002), who, on the basis of an extensive review of the L2 literature, has claimed that child L1 learners and adult L2 learners approach collocation in fundamentally different ways.

When exposed to language input, Wray claims, the adult second language learner primarily notices and remembers not meaningful chunks, but individual words. Whereas a first language learner, on encountering a collocation such as major catastrophe, would note the string as a single sequence, and remember it as the idiomatic way to refer to 'large disasters', the adult learner would instead 'break it down into a word meaning "big" and a word meaning "disaster" and store the words separately, without any information about the fact they went together'. If called on to talk about major catastrophes in the future, 'they would have no memory of major catastrophe as the pair originally encountered, and any pairing of words with the right meaning would seem equally possible' (2002: 206-09).

This fundamental difference between child L1 learners and adult L2 learners comes about, Wray suggests, due to a convergence of social and cognitive factors. On the social side, adult learners (especially those in a classroom environment) rarely have the pressing need to communicate that drives L1 learners to memorize helpful communicative sequences. Indeed, since in many cases the surrounding social pressure may be largely from the L1, rather than the L2 community, it may actively discourage the adoption of nativelike formulas. These effects will be further compounded by traditional classroom teaching methods, which often focus on form and the introduction of new words. On the cognitive side, the mature mental faculties of adult learners - and, in particular, the fact that they are likely to be literate, and therefore aware of the word as a basic unit of language - will mean that they are likely to feel uncomfortable not knowing how sequences break down into their component words (2002: 205-06). While it is possible to overcome these influences (so that learners do occasionally achieve full nativelike competence), this will be rare given the 'great many obstacles which their social and intellectual experience and their learning situations will set up to prevent it' (2002: 213).

Though the adverse social factors described apply mainly to classroom learners, so that 'for adult learners in a naturalistic setting, 
socio-interactional pressures will encourage the adoption of some formulaic sequences' (2002: 205), the cognitive factors apply to both types of adult learner. Because of their 'awareness of the word as a possible unit of linguistic processing', Wray contends, naturalistic learners, as well as classroom learners, will tend to 'feel uncomfortable with not knowing how a memorized string breaks down' (2002: 206) and so will fail to store sequences as wholes.

Wray does, at some points, allow the possibility that, for advanced learners, there may be 'some means of building up the store of nativelike formulaic sequences post hoc, probably by residing and fully interacting for some time in the L2 environment' (2002: 210). Little indication is given, however, as to how this post hoc building-up of formulas takes place. The closest Wray comes to spelling out a position is the statement that, whereas L1 collocations are 'fully formulaic pairings which have become loosened ... the adult learner's collocations are to be seen as separate items which become paired' (2002: 211). However, she does not describe how this pairing up might occur.

One possibility is that pairing is driven by an implicit tallying of transformation probabilities, in the manner suggested by Ellis. This does not seem to be what Wray has in mind, however. She maintains that the pairing-up process leads to 'characteristic difficulties' with non-native collocations; in particular to difficulties in establishing appropriate 'strengths of association' between words (2002: 211). If the pairing-up process were a matter of implicitly tallying input, it is not clear why it would have such consequences: adult learners who implicitly retained memories of the words that go together in their input ought to establish strengths of association that are appropriate to that input. Wray's position appears, rather, to be that, having noticed a shortfall in their knowledge, learners attempt to build up a stock of collocations through intentional memorization of formulas. Such intentional learning would not be tuned to input, and so the appropriate association strengths would not be established. In short, although Wray allows that some advanced learners may acquire a knowledge of collocation, this knowledge is attained in a way that is different in kind (and, accordingly, has a characteristically different result) from that of first language learners.

If Wray's model is right, it is of significant theoretical and practical importance. Usage-based models such as Ellis's suggest that the implicit tallying of collocational probabilities is no mere linguistic sideshow, but rather central to the process of language acquisition across all levels of linguistic description (Ellis, 2001: 41). If this mechanism 
is not normally employed by adults, this may go much of the way to explaining the significant differences between the two sets of learners across the linguistic spectrum. On the practical side, it will mean that the adult second language classroom should not - as many approaches have advocated (e.g. Willis, 1990; Nattinger and DeCarrico, 1992; Lewis, 1993) - aim to emulate child L1 learning by exposing students to targeted formulaic sequences in the hope that these will feed in to acquisition. Adults, Wray argues, may need to take a different route to fluency, perhaps by a process of proceduralization involving the automated planning and assembly of utterances (2002: 201, 211).

The current state of evidence on this matter makes the two models of learning rather difficult to evaluate. The majority of research in this area has taken the form of either learner-corpus studies (Yorio, 1989; De Cock et al., 1998; Granger, 1998; Howarth, 1998; Lorenz, 1999; Kaszubski, 2000; Oppenheim, 2000; Foster, 2001; Adolphs and Durow, 2004; Nesselhauf, 2005), or pen-and-paper tests of collocational knowledge (Scarcella, 1979; Biskup, 1992; Bahns and Eldaw, 1993; Farghal and Obeidat, 1995; Granger, 1998). Wray's claim that adult learners fail to remember collocations is based on a general sense that the ability learners have shown in these evaluations is 'lagging behind' their general knowledge of grammar and vocabulary (Wray, 2002: 207). However, as Wray herself acknowledges, this is a rather impressionistic conclusion. It is difficult to see how we could specify a level of collocational knowledge that would be properly 'on a par with' any particular level of grammatical/vocabulary knowledge. There is simply no baseline defining what level of collocational knowledge learners should achieve after a certain level of experience with a language. ${ }^{1}$ Given the relative rarity of occurrence of individual collocations (in comparison with that of individual words), however, it seems sensible to expect collocation learning to take a relatively long time. Indeed, since learning a collocation will involve retaining some memory trace of any particular word pair met until that pair is met again, it may be that the relatively sparse nature of most second language input (totalling to perhaps a few hours a week) will mean that the extended time that elapses between two exposures to a collocation is usually too long

${ }^{1}$ L2 learners typically vary greatly in their learning of vocabulary, which makes it difficult to establish expectations for how much lexical learning should occur for a set period of instruction/exposure. For example, Laufer (2000) reports rates varying from three words per hour in Germany (vocabulary size of 1200 reached in 400 hours of schooling) down to 1.35 per hour (1220 in 900 hours) in Indonesia. 
and that trace will be lost, with the result that learning of any but the most frequent collocations can never properly get off the ground.

In order to evaluate whether learners retain the collocations they encounter in their input, it is necessary to compare a description of a learner's knowledge with a description of the input they have received. From this perspective, it is a major shortcoming of the studies cited above that they fail to provide any consideration of input, instead focusing entirely on what learners know. That is to say, they look only at the product of learning, without considering the process. One way of getting the information we need would be to compare learners' performance with an estimate of the input they are likely to have had. This is the approach taken by Durrant and Schmitt (2009), which examines the use made by learners of collocations with various levels of frequency in the British National Corpus (BNC). They find that adult non-native learners do in fact make extensive use of collocations that are frequent in English (i.e. collocations that typically attain high $t$-scores, such as good example, long way and hard word), but that their writing retains a sense of collocational 'inauthenticity' because of their failure to use lower-frequency, but strongly associated forms (i.e. collocations that typically attain high mutual information scores, such as densely populated, bated breath, and preconceived notions), which are likely to be highly salient for native speakers. These results appear to be consistent with the view that learners acquire those collocations to which they are frequently exposed. However, Durrant and Schmitt's methodology has the weakness of assuming that the contents of the BNC represent a good approximation to the input learners receive; an assumption that is clearly open to question. It would, of course, be highly desirable to study knowledge of collocations in a situation in which we have total knowledge of the input a learner has received. This is probably impossible, however. As Hoey (2005: 14) has noted, "the personal "corpus" that provides a language user with their lexical primings is by definition irretrievable, unstudiable and unique.'

An alternative approach is to observe the effects of input in a labbased setting. While laboratory research is always open to objections regarding contextual validity, such an approach has the advantage of allowing researchers to strictly control the input learners receive within a short time-frame and to test the knowledge retained. This approach can profitably be used in concert with more contextually valid, but lesstightly-controlled data, such as those reported by Durrant and Schmitt, to 
build a robust composite picture of the learning process. Following this logic, the study reported here aims to find out whether adult non-native learners of English retain information about the collocational contexts of words that they meet in their input through a lab-based training and testing experiment.

\section{Methodology}

\section{Design}

This study will carefully control the input L2 learners receive of target word pairs, and then test their retention of those pairs. Participants will undergo a short training session in which they are exposed to a number of target adjective-noun combinations embedded in sentences. They will then undergo a cued recall test to see whether memory for target nouns is facilitated by the presence of their paired target adjectives. Any such facilitation will serve as evidence that an association had been formed between the paired words in training.

The study will look at learning under three different conditions. In the first condition, participants are exposed to collocations in a sentence context one time only. Presumably, a single exposure to a word combination is unlikely to have a lasting impact on a learner's language system. Combinations that are encountered once and never met again are not collocations in the sense in which that term is used in this study. Collocations are, rather, those combinations that the language user meets repeatedly over time and that for this reason come to be retained as more-or-less permanent features of the speaker's linguistic knowledge. However, as Goldberg (2007) has noted, if the effects of repetition over time are ever to be felt, some memory trace must be left by even a single exposure to a stretch of language. Without such a trace, the learning process could never get started. This first condition aims to test for such a trace.

The second and third conditions examine the effects of different types of repetition on learning. Most individual collocations are - compared to individual words - relatively rare, and for the native speaker repeated exposure to important collocations will be provided only through an extended period of immersion in the language. Since most adult learners do not have the luxury of such extensive input, teachers may wish to shortcut this process somewhat by providing 'artificially-enriched' input in which learners encounter target collocations repeatedly in a 
short space of time. At least two different types of repetition could be envisaged here. The first is verbatim repetition of a single linguistic context. That is, the learner could engage with one piece of language a number of times over. Repeated exposure of this sort to a single stretch of language can be seen as a form of fluency-building activity. A learner's initial contact with a piece of language is likely to involve a number of pressing cognitive demands - recognizing the words, decoding the syntax, creating a plausible semantic context and deriving a meaning - which may inhibit any actual learning. A second exposure to the same stretch of language, with these issues at least partially resolved in the learner's mind, may enable the learner to focus more on consolidating and building fluency with the language. This is the rationale behind such recommended collocation-consolidating activities as '4-3-2 minute talks', in which learners are asked to repeatedly repeat a particular talk in increasingly shorter lengths of time (Hill et al., 2000: 90-91).

A second type of repetition is the repeated use of a target collocation in different sentence contexts. In this scenario, the learner's cognitive burden may remain relatively high at the second encounter. However, the fact that the learner meets two stretches of language in which only the collocation remains constant will presumably make that collocation much more salient for the learner than it would otherwise be. This may be a distinct advantage over the first type of repetition, in which there is nothing to direct the learner's attention to the target collocations, rather than to any other aspect of the sentences they encounter. The second and third experimental conditions in this study aim to examine the effects of each of these types of repetition.

For all three conditions, the testing phase of the experiment consists of a naming task. For each item in the test, learners will first be shown an adjective part of one of the adjective-noun pairs. Immediately afterwards, they will be shown the first two letters of the noun part, followed by dashes for the missing letters. They will be asked to say the noun aloud if they recognize it. If nouns are recognized more reliably when they follow an adjective with which they were paired during training, this will be taken as evidence that some memory has been retained of the two words' co-occurrence. It should be noted that this test is not designed to assess all aspects of collocation knowledge. Rather, it aims to determine whether learners have established an association between the two words involved. 


\section{Materials}

To create target adjective-noun pairs for learning, a number of nouns were first selected according to the following criteria:

- All nouns appear in the BNC with a lemmatized frequency of between 50 and 100 occurrences per million words. This places them within the top 2150 most frequent words in the corpus but outside of the top 1100 (Leech et al., 2001). This criterion aims to ensure that subjects are likely to have some familiarity with the words while avoiding the ceiling effects associated with very high frequency forms.

- All nouns are four or five letters in length. In the testing phase of the experiment, subjects will be asked to complete words from twoletter onsets (e.g. $E V_{-}{ }_{-}$for event); words of similar lengths were therefore used since words of very different lengths would be likely to make this task more difficult for some words than for others.

- The word-completion task may also be affected by the number of other words sharing the same onset as the target (e.g. $R O_{-}$- could be completed by a large number of alternative words - road, rock,

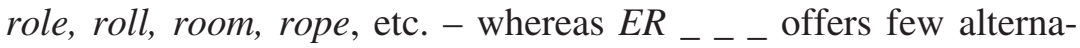
tives to error). To control for this, we determined how many nouns with lemma frequencies of at least 15 per million in the BNC shared the same onset as the target noun; nouns which shared an onset with fewer than 10 or more than 30 other items were not included. We also checked how many words both shared an onset with the target noun and contained the same number of letters (such that they could actually be substituted for the target in the task); nouns with fewer than three or more than nine such possible substitutes were also excluded.

Second, target adjectives were selected according to the following criteria:

- All adjectives appear in the BNC with a frequency of between 50 and 100 occurrences per million words. As with the nouns, this aims to ensure that the words are known to subjects without being over-frequent.

- Since strong pre-existing collocational associations of the adjectives may affect the testing phase, any adjectives that were likely to have such associations were excluded; i.e. any adjectives which are followed by one particular noun in 5\% or more of their occurrences in the BNC were excluded. 
The selected nouns and adjectives were then combined into 20 target word pairs that fulfilled the following conditions:

- All pairs appear with zero or low frequency (i.e. one or two occurrences) in the BNC. This condition aims to ensure that subjects are unlikely to have formed any collocational association between the words prior to training.

- All pairs were judged by the researchers to be meaningfully combinable in plausible contexts.

A number of different sentences were then created containing each target pair. Twelve native speakers of English were asked to rate each of these sentences on a 6-point Lickert scale according to how 'natural' they were ( $1=$ 'very unnatural', $6=$ 'completely natural'). Only sentences receiving a mean rating of five or above were retained. From the retained sentences, 40 were selected for use in the final materials: two sentences for each of 20 target word pairs. Additionally, 40 matched 'control sentences' were also created. These were identical to the training sentences except for the target word pair. In each case, the target noun was kept, but the adjective was either deleted or - if deletion made the sentence unnatural or nonsensical - replaced by a different adjective (none of which had been used in any of the target sentences). For example, the target sentence for the target pair busy route was Extra buses were introduced on the busy route into the city, and it was matched with the control sentence Extra buses were introduced on the route into the city. Likewise, the target sentence Hot chocolate is an excellent drink on a cold evening was matched with the control Hot chocolate is $a$ wonderful drink on a cold evening (target pair $=$ excellent drink).

To create the training materials, these sentences were divided into two sets, with each set containing 20 training sentences (one for each of the 20 target pairs), plus 20 matched control sentences. Each of the two sentence sets was further divided into two counterbalanced experimental lists, each containing 10 target sentences and 10 control sentences, with nouns that appear in a training sentence in one list appearing in their control sentence in the other, and vice versa. For both lists, the 10 training sentences included six with five-letter target nouns and four with four-letter target nouns. Two groups of 20 'filler sentences' were also created - one for each of the two main training sets - and added to each list. Each filler sentence included a noun of 4-5 letters from the same 50-100 occurrences/million band as the target nouns. In this way, 
the final materials consisted of two sets of two counterbalanced lists, with each list containing:

- 10 sentences containing a target word pair;

- 10 sentences containing only the noun part of a target word pair;

- 20 sentences containing other nouns.

None of the target nouns or adjectives was used in any sentence other than their training or control sentence. No lexical words were used in any of the sentences that shared a two-letter onset with any of the target nouns. The four experimental lists are shown in Appendix 1.

\section{Participants}

The participants consisted of 84 non-native speakers of English (56 female, 28 male). All were undertaking taught postgraduate courses at the University of Nottingham at the time of the experiment. The mean age of participants was 25.1 (maximum $=41$, minimum $=19$ ). Participants came from the following L1 backgrounds: Mandarin (26), Thai (6), Malay (5), Serbian (5), Arabic (4), Cantonese (4), Hindi (3), Kiswahili (3), Russian (3), Spanish (3), Igbo (2), Indonesian (2), Japanese (2), Marathi (2), Telugu (2), Gujarati (1), Hungarian (1), Italian (1), Kazakh (1), Kinyarwandan (1), Melayalam (1), Persian (1), Portuguese (1), Singhalese (1), Slovene (1), Vietnamese (1) and Yoruba (1). Although no standardized measure of L2 proficiency was available for each student at the time of the study, the University of Nottingham has an entry requirement of 6.0 IELTS or 550 TOEFL (paper version), and so the students can be assumed to be reasonably proficient in English.

\section{Procedure}

Participants were assigned in equal numbers to one of the three training conditions: single exposure, verbatim repetition and varied repetition. Within each condition, participants were in turn assigned in equal numbers to one of the two counterbalanced experimental lists. In this way, half of the participants in each condition saw 10 of the 20 target collocations. They saw the other 10 target nouns in control sentences, without their paired adjectives. For the other half of the participants, this situation was reversed: the target nouns that the first group had seen alone were presented with their adjective pairs, while the nouns that the first group had seen with their pairs were seen in control sentences. 
In the single exposure condition, participants only saw sentences from the first of the two sets of training materials. That is, each participant saw 40 sentences, including 10 in which target nouns appeared together with their paired adjectives, 10 in which target nouns appeared without their paired adjectives and 20 filler sentences. Sentences were presented to participants on a computer screen in random order. Before each sentence, participants were presented with a fixation point ('+') for 2 seconds. This was then replaced with the sentence, which remained on screen for 7 seconds. Participants were instructed to read the sentence aloud into a headset-mounted microphone. After 7 seconds the sentence disappeared and they were invited to press a button on the computer keyboard to continue to the next item. The training phase lasted approximately $7-8$ minutes.

In the verbatim repetition condition, participants were again exposed only to sentences from the first of the two sets of training materials. This time, however, each sentence was presented twice. The training began identically to that in the single exposure condition, with sentences being presented in random order for 7 seconds each and participants instructed to read the sentences aloud. On completion of this phase, participants were told that they would be asked to repeat the process at a faster rate. The same sentences were then re-presented in the same way and in a new random order, but this time participants were only given 3 seconds to read each sentence. This condition was intended to focus students on fluent production of the sentences, as might be the case if such a repetition task was used in a classroom environment. The training phase lasted approximately 11-12 minutes.

In the varied repetition condition, participants were exposed to sentences from both sets of training materials. That is, each participant saw 80 different sentences, including 20 in which target nouns appeared together with their paired adjectives (two different sentences for each of 10 different targets), 20 in which target nouns appeared without their paired adjectives (again, two sentences for each of 10 different targets) and 40 filler sentences. The training again began identically to that in the previous two conditions, with sentences from the first training set being presented in random order for 7 seconds each and participants reading each sentence into the microphone. On completion of this phase, participants were told that they were half way through and invited to re-commence in their own time. In the second phase, sentences from the second training set were presented, again in random order and for 
7 seconds each, with participants reading each sentence aloud into the microphone. The training phase lasted approximately 14-15 minutes.

On completion of the training, participants moved directly to the testing phase of the experiment. Testing took the form of a naming task (based loosely on the tasks used in Schooler and Anderson, 1997), in which subjects first saw a fixation point ('+') for 1.5 seconds, followed by the adjective part of one target adjective-noun pair, presented in lower-case letters (e.g. 'warm'), which also remained onscreen for 1.5 seconds. This was immediately followed by the onset of the noun from the same pair, in upper-case letters (e.g. 'FL_ _'; for the noun flat). The onset remained onscreen for 5 seconds. Participants were told that the upper-case word onset would be a word from one of the sentences they had just read and were instructed to say the word into the headset-mounted microphone if they thought they knew what it was. Participants were not informed of any connection between the adjective and the target noun. The test administrator noted whether a correct or incorrect response had been given. The test started with four practice items (using nouns from the filler sentences), followed by a main test consisting of 20 items - one for each target word pair - presented in random order. The same test items were presented to all participants.

\section{Results and discussion}

Since participants had seen all target nouns either once (in the single repetition condition) or twice (in the other conditions) each, recall for all nouns should have been the same, other things being equal. However, if some memory had been retained from the training phase of the pairings between the target adjectives and nouns, then the adjective prime should have provided participants with an additional memory cue for those nouns they had seen together with their adjective partners. Thus, we can expect some level of recall for all nouns, but if participants had formed an association during training between the two parts of the target pairs, their recall should have been better for those nouns that they had seen with their adjective pairs than for those nouns that they had seen only in control sentences.

Table 1 shows the minimum, maximum and median number of correct identifications of target nouns in control and collocation conditions for each of the three training types (median scores are presented because scores were not normally distributed within conditions). The median scores are also presented visually in Figure 1. 
178 Adult learners' retention of collocations from exposure

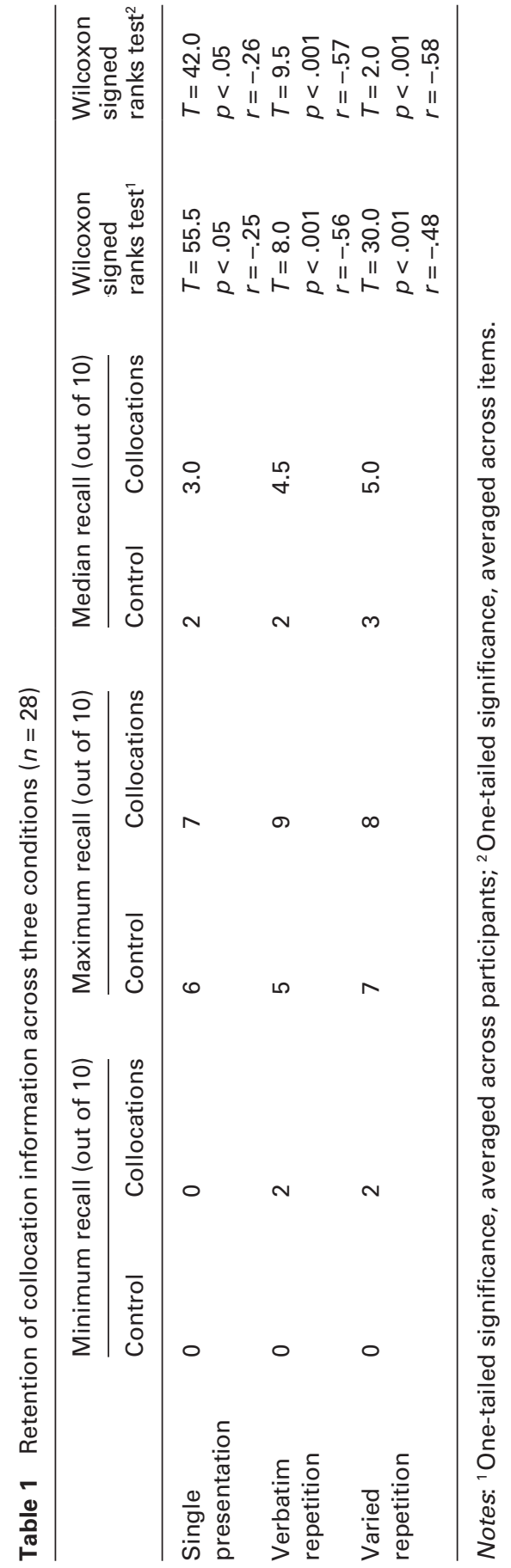




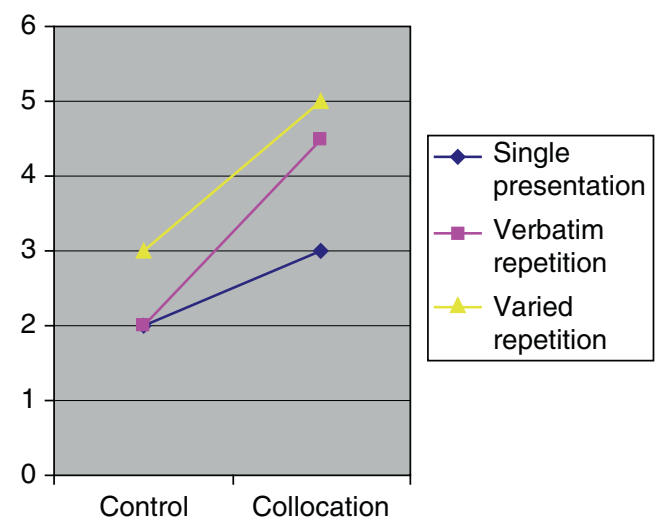

Figure 1 Retention of collocation information across three conditions

In all three training conditions, nouns that had been seen together with their paired adjectives during the training phase were remembered significantly more frequently than those that had not. The strength of this effect was, as we would expect, weakest for those participants who had received only a single exposure to the target collocations. The effect size was -.25 , which falls below Cohen's benchmark of .3 for a medium effect (Field, 2005), and so must be considered a small effect. However, even these participants did retain some memory of the co-occurrence of the adjective-noun pairs they met in training, in spite of the facts that they saw each pair only once in an 8-minute training phase and that they had not been told that they would be asked to recall anything about the language they read. We can conclude, therefore, that adult second language learners do - in contrast to Wray's claims - retain some memory of which words go together in the language they meet. Since this retention appears to occur implicitly - i.e. without the conscious intention of the learner - this suggests that adult L2 learners are likely to gather information about the collocations in their input, regardless of any intentional study techniques or strategies. This suggests that any shortcomings in non-natives' grasp of collocational links between words may be a product of an insufficient exposure to the target language, rather than of a distinctively 'word-based' approach to learning.

Unsurprisingly, both of the repetition training conditions yielded superior levels of recall in comparison to the single presentation condition. When comparing the repetition conditions to each other, the verbatim repetition condition appears to have some advantage over the varied repetition condition. Although there is little effect size difference when averaged across 
items (.57 vs. .58), when averaged across participants the effect size for verbatim repetition was .56 vs. .48 for varied repetition. Cohen's criterion for a large effect is .5 (Field, 2005), and both repetition conditions either closely approach or exceed this, so the effect of minimal repetition of collocation input (only two repetitions) in facilitating collocation recall can be considered large. Thus both the verbatim and varied conditions in this study appear to be effective means of establishing initial collocation memory traces, with verbatim repetition being slightly more effective.

This superiority of verbatim repetition over varied repetition is also shown when comparing the 'gain' in recall across the two conditions (where gain is defined as the recall for control nouns subtracted from the recall for collocating nouns). Gain in the verbatim repetition condition $(M d n=2)$ is confirmed to be significantly greater than that in the varied repetition conditions $(M d n=1.5, U=123.5, p$ (two-tailed) <.05, $r=-.33$; note that the use of median scores for this non-parametric data means that the average of all gain scores is not exactly equal to the difference between average control and average target scores presented in Table 1). It seems, then, that the fluency-oriented repetition of a single sentential context yielded better collocation learning than exposure to alternative contexts, with a medium effect size (i.e. $>$.3). Although our study was not designed to explain this advantage, we can speculate that the cognitive ease of reading an identical sentence the second time around somehow makes it easier to form a collocational memory trace. Alternatively, perhaps the timed nature of the fluency-based verbatim condition somehow increased the participants' attention on the language, leading to better results, even though less time was spent on the input ( 7 minutes +3 minutes for the verbatim condition; $7+7$ minutes for the varied condition). Further research will be required to disambiguate these possibilities and to further our understanding of the most effective methods of facilitating collocation knowledge.

Our results raise a number of other important issues for future research. In this study, testing took place immediately after training. However, attrition of lexical knowledge is a widely reported phenomenon. It would be very interesting to discover how durable the reported memory traces are. It is especially important for pedagogical reasons to establish the length of time before the initial trace 'disappears', as subsequent exposures need to be received in time to build upon the previous knowledge, otherwise the learner would be forever 'starting over' in the effort to establish collocation knowledge. Detecting a level of retention below which learners could be counted as 'starting over', however, would probably require 
more subtle tests of association than are used in the present study; the 'savings' methodology employed in lexical attrition studies (e.g. Hansen et al., 2002), for example, might be used. It would also be interesting to establish how many exposures are typically required for stable, longterm associations to become established. Research from reading indicates that new words need to be seen around 8-10 times in order to be learned (Schmitt, 2008), and it would be surprising if collocation knowledge could be acquired in any fewer exposures. Research establishing how many exposures are required in what length of time for collocation learning to take place would certainly be useful for pedagogy.

Also, this study dealt with implicit learning only. As explicit attention is widely acknowledged to facilitate lexical learning, it can only be assumed that an explicit focus on target collocations would dramatically improve their acquisition. Moreover, the learners in this study were required only to engage with the training sentences at a 'formal' level, i.e. by reading the sentences aloud. As was noted above, Ellis (2005) maintains that meaning can play an important role in collocation learning. It would therefore be interesting to see what effect different types of meaning-focused training tasks would have on acquisition. Additionally, the knowledge we have assessed is only knowledge that there is a formal connection between the two words involved in each collocation. No assessment has been made here of how well the meaning and use of the collocations have been learned. Future research should also include a consideration of these other aspects of collocation knowledge.

Finally, this study has looked only at how learners come to establish associations between words that they are already assumed to know. It is possible that somewhat different processes will be involved for collocations of previously unknown words. It would be interesting for future research to address this issue.

As they stand, our results suggest a number of pedagogical implications. First, although learners can form initial memory traces from a single exposure, it appears that repetition is very effective in improving the learning. Thus, teachers should devise materials in which the target collocations are met several times within a relatively short period of time. Second, it seems that - at least in the early stages of collocation learning - verbatim repetition has some advantage over varied repetition, so teachers using fluency-based re-reading exercises can expect collocational improvement to accrue from such exercises in addition to reading fluency. Third, while learning did occur from two repetitions in this study, the students were still only able to demonstrate knowledge 
of a small number of target collocations. This suggests that learners will need substantial exposure to a second language in order to gradually build up knowledge of a large number of collocational pairs.

\section{Conclusions}

The results seen in this study suggest that adult learners of English as a second language do retain information about what words appear together in the language to which they are exposed. This accords with evidence from learner-corpus research (Durrant and Schmitt, 2009), which has shown that advanced non-native speakers of English do make use of collocations that are likely to have been frequent in their input. Taken together, these results suggest that adult L2 learners do not, as Wray has claimed, focus their learning entirely on individual words. Rather, as Ellis's L1 model predicts, learners retain a memory of collocational chunks from the language to which they are exposed. Any deficit in learners' knowledge of collocation is therefore more likely to be the result of insufficient exposure to the language than of a fundamentally different approach to learning.

We have also seen that the fluency-oriented repetition of individual sentence contexts has a greater impact on collocation learning than does exposure to the same collocations in different contexts. Teachers wishing to foster their students' collocation learning may therefore wish to give special emphasis to activities in which learners have the opportunity to encounter the same language several times, enabling them to focus on building up fluency with particular strings of language without the 'distractions' of dealing with new contexts and meanings.

\section{References}

Adolphs, S. and Durow, V. 2004: Social-cultural integration and the development of formulaic sequences. In Schmitt, N., editor, Formulaic sequences: acquisition, processing and use. Amsterdam: John Benjamins.

Bahns, J. and Eldaw, M. 1993: Should we teach EFL students collocations? System 21, 101-14.

Biber, D., Conrad, S. and Cortes, V. 2004: If you look at ...: lexical bundles in university teaching and textbooks. Applied Linguistics 25, 371-405.

Biskup, D. 1992: L1 influence on learner's renderings of English collocations: a Polish/German empirical study. In Arnaud, P.J.L. and Bejoint, H., editors, Vocabulary and applied linguistics. Basingstoke: Macmillan. 
De Cock, S., Granger, S., Leech, G. and Mcenery, T. 1998: An automated approach to the phrasicon on EFL learners. In Granger, S., editor, Learner English on computer. London: Addison Wesley Longman.

Durrant, P. and Schmitt, N. 2009: To what extent do native and non-native writers make use of collocations? International review of applied linguistics 47, 157-77.

Ellis, N.C. 2001: Memory for language. In Robinson, P., editor, Cognition and second language instruction. Cambridge: Cambridge University Press.

- 2002: Reflections on frequency effects in language processing. Studies in Second Language Acquisition 24, 297-339.

- 2003: Constructions, chunking, and connectionism: the emergence of second language structure. In Doughty, C.J. and Long, M.H., editors, The handbook of second language acquisition. Oxford: Blackwell.

- 2005: At the interface: dynamic interactions of explicit and implicit language knowledge. Studies in Second Language Acquisition 27, 305-52.

Ellis, N.C. and Larsen-Freeman, D. 2006: Language emergence: implications for applied linguistics: introduction to the Special Issue. Applied Linguistics 27(4), 558-89.

Farghal, M. and Obeidat, H. 1995: Collocations: a neglected variable in EFL. International Review of Applied Linguistics in Language Teaching 33, 315-31.

Field, A. 2005: Discovering statistics using SPSS. London: Sage.

Firth, J.R. 1968: A synopsis of linguistic theory, 1930-55. In Palmer, F.R., editor, Selected papers of J.R. Firth 1952-59. Harlow: Longman.

Foster,P. 2001: Rules and routines: a consideration of their role in the task-based language production of native and non-native speakers. In Bygate, M., Skehan, P. and Swain, M., editors, Researching pedagogic tasks: second language learning, teaching and testing. London: Longman.

Goldberg, A.E. 2006: Constructions at work: the nature of generalization in language. Oxford: Oxford University Press.

- 2007: Learning the general from the specific. Paper presented at the UWM linguistics symposium on formulaic language, University of Wisconsin, Milwaukee, WI.

Granger, S. 1998: Prefabricated patterns in advanced EFL writing: collocations and formulae. In Cowie, A.P., editor, Phraseology: theory, analysis, and applications. Oxford: Oxford University Press.

Hansen, L., Umeda, Y. and Mckinney, M. 2002: Savings in the relearning of second language vocabulary: the effects of time and proficiency. Language Learning 52, 653-78.

Hill, J., Lewis, M. and Lewis, M. 2000: Classroom strategies, activities and exercises. In Lewis, M., editor, Teaching collocations: further developments in the lexical approach. Boston, MA: Thomson.

Hoey, M. 1991: Patterns of lexis in text. Oxford: Oxford University Press. 
2005: Lexical priming: a new theory of words and language. London: Routledge.

Howarth, P. 1998: The phraseology of learners' academic writing. In Cowie, A.P., editor, Phraseology: theory, analysis, and applications. Oxford: Oxford University Press.

James, W. 1890: The principles of psychology. New York: Holt.

Jones, S. and Sinclair, J.M. 1974: English lexical collocations: a study in computational linguistics. Cahiers de lexicologie 24, 15-61.

Kaszubski, P. 2000: Selected aspects of lexicon, phraseology and style in the writing of Polish advanced learners of English: a contrastive, corpus-based approach. Unpublished PhD dissertation, Adam Mickiewicz University, Poznán.

Laufer, B. 2000: Task effect on instructed vocabulary learning: the hypothesis of 'involvement'. Selected papers from AILA 99 Tokyo. Tokyo: Waseda University Press.

Leech, G., Rayson, P. and Wilson, A. 2001: Word frequencies in written and spoken English: based on the British National Corpus. London: Longman.

Lewis, M. 1993: The lexical approach: the state of ELT and a way forward. London: Thomson Heinle.

—, editor, 2000: Teaching collocations: further developments in the lexical approach. Boston, MA: Thomson.

Lorenz, G. 1999: Adjective intensification: learners versus native speakers: a corpus study of argumentative writing. Amsterdam: Rodopi.

Manning, C.D. and Schütze, H. 1999: Foundations of statistical natural language processing. Cambridge, MA: MIT Press.

Miller, G.A. 1956: The magical number seven, plus or minus two: some limits on our capacity for processing information. Psychological Review 63, 81-97.

Nattinger, J.R. and DeCarrico, J.S. 1992: Lexical phrases and language teaching. Oxford: Oxford University Press.

Nesselhauf, N. 2005: Collocations in a learner corpus. Amsterdam: John Benjamins.

Oppenheim, N. 2000: The importance of recurrent sequences for nonnative speaker fluency and cognition. In Riggenbach, H., editor, Perspectives on fluency. Ann Arbor, MI: University of Michigan Press.

Palmer, H.E. 1933: Second interim report on English collocations. Tokyo: Kaitakusha.

Scarcella, R. 1979: Watch up!: a study of verbal routines in adults second language performance. Working papers on Bilingualism 19, 79-88.

Schmitt, N., editor, 2004: Formulaic sequences: acquisition, processing and use. Amsterdam: John Benjamins. 
- 2008: Instructed second language vocabulary learning. Language Teaching Research 12, 329-63.

Schooler, L.J. and Anderson, J.R. 1997: The role of process in the rational analysis of memory. Cognitive Psychology 32, 219-50.

Sinclair, J.M. 1987: Collocation: a progress report. In Steele, R. and Threadgold, T., editors, Language topics: essays in honour of Michael Halliday. Amsterdam: John Benjamins.

1991: Corpus, concordance, collocation. Oxford: Oxford University Press. 2004: The search for units of meaning. Trust the text: language, corpus and discourse. London: Routledge.

Stubbs, M. 1995: Collocations and semantic profiles: on the cause of the trouble with quantitative methods. Functions of language 2, 1-33.

Willis, D. 1990: The lexical syllabus. London: Harper Collins.

Wray, A. 2002: Formulaic language and the lexicon. Cambridge: Cambridge University Press.

Yorio, C.A. 1989: Idiomaticity as an indicator of second language proficiency. In Hyltenstam, K. and Obler, L.K., editors, Bilingualism across the lifespan. Cambridge: Cambridge University Press. 
Appendix 1 Training materials

\section{Set One}

List One

\begin{tabular}{ll}
\hline Sentence & Type \\
\hline You can buy a cheap ball from that shop on the corner. & target collocation \\
How big is the average brain? & target collocation \\
Hot chocolate is an excellent drink on a cold evening. & target collocation \\
They live on a quiet farm in Kent. & target collocation \\
We couldn't open the huge gate. & target collocation \\
This is the only clean lake in the area. & target collocation \\
He had a thick, powerful neck. & target collocation \\
The bells made a lovely soft noise in the distance. & target collocation \\
Extra buses were introduced on the busy route into the city. & target collocation \\
He wrote a detailed text, explaining everything fully. & control \\
She worked on an emergency supply boat. & control \\
She was looking forward to getting home to her flat. & control \\
Wherever I go, I find that these maps are a very useful guide. & control \\
The afternoon heat made us sweat. & control \\
She found an old leaf. & control \\
She thought the radio was a waste of money. & control \\
There had been a rise in the cost of living. & control \\
He skied down the mountain at high speed. & control \\
He wanted to go on a tour of the Middle East. & control \\
He always found it difficult to choose a wine. &
\end{tabular}

Notes: Target nouns and their paired adjectives are highlighted here in bold; they were not highlighted in the training materials seen by participants.

List Two

Sentence

Type

She found a beautiful leaf.

He skied down the mountain at a dangerous speed.

Wherever I go, I find that these maps are a very effective guide.

She thought the expensive radio was a waste of money.

She worked on an emergency medical boat.

There had been an obvious rise in the cost of living.

He wanted to go on a religious tour of the Middle East.

The southern heat made us sweat.

He always found it difficult to choose a suitable wine.

She was looking forward to getting home to her warm flat.

How big is the human brain?

Extra buses were introduced on the route into the city.

You can buy a ball from that shop on the corner.

This is the only lake in the area.

target collocation

target collocation

target collocation

target collocation

target collocation

target collocation

target collocation

target collocation

target collocation

target collocation

control

control

control

control

He wrote a long text, explaining everything fully.

control

Hot chocolate is a wonderful drink on a cold evening.

control

We couldn't open the gate.

control

He had a thick, short neck.

control

They live on a farm in Kent.

control

The bells made a lovely noise in the distance.

control 
There are lots of different types of birds in the park. The Earth is around four point five billion years old. The police were keeping a file on his activities.

There was a car in front of the house.

She is a good judge of character.

We had a lovely meal yesterday.

He used to have a model horse made of wood.

Every time he opens his mouth he says something stupid.

The dog escaped through a hole in the fence.

The shops were crowded during the January sale.

We went to America by ship.

I've got an old tape of her singing.

Crime in the city had increased sharply.

Have you seen this video?

That club has a five pound entry charge.

She lost her phone when she was on holiday.

There is a one hundred pound overdraft limit.

He always wears a gold watch.

I damaged a plate when I was washing up.

I'm going for a walk after dinner.

\section{Set Two}

List One

\begin{tabular}{|c|c|}
\hline Sentence & Type \\
\hline It was only a cheap ball, but he was sorry to lose it. & target collocation \\
\hline $\begin{array}{l}\text { The average brain must get about five to six hours sleep } \\
\text { a night to work well. }\end{array}$ & target collocation \\
\hline Lemon and honey is an excellent drink if you have a cold. & target collocation \\
\hline He owns a house by a quiet farm. & target collocation \\
\hline He pushed open the huge gate at the end of the path. & target collocation \\
\hline There was a clean lake where the children could swim. & target collocation \\
\hline $\begin{array}{l}\text { They were impressed by the athlete's powerful neck } \\
\text { and shoulders. }\end{array}$ & target collocation \\
\hline The soft noise of the door opening downstairs woke her up. & target collocation \\
\hline $\begin{array}{l}\text { The busy route between Birmingham and London was } \\
\text { closed for a week. }\end{array}$ & target collocation \\
\hline She read the detailed text carefully. & target collocation \\
\hline They went to the island on a passenger boat. & control \\
\hline He loved to sit in his flat and watch the snow outside. & control \\
\hline This is a simple and practical guide to computer programming. & control \\
\hline He loved the summer heat. & control \\
\hline There was one leaf still on the tree. & control \\
\hline I got her a radio for her birthday. & control \\
\hline They had seen a huge rise in their standards of living. & control \\
\hline The police stopped her for going at an illegal speed. & control \\
\hline She went on a long tour, visiting all the churches in the region. & control \\
\hline Can you recommend a wine to have with fish? & control \\
\hline
\end{tabular}


List Two

\begin{tabular}{|c|c|}
\hline Sentence & Type \\
\hline They went to the island on a medical boat. & target collocation \\
\hline He loved to sit in his warm flat and watch the snow outside. & target collocation \\
\hline $\begin{array}{l}\text { This is a simple and effective guide to computer } \\
\text { programming. }\end{array}$ & target collocation \\
\hline He loved the southern heat. & target collocation \\
\hline There was one beautiful leaf still on the tree. & target collocation \\
\hline I got her an expensive radio for her birthday. & target collocation \\
\hline They had seen an obvious rise in their standards of living. & target collocation \\
\hline The police stopped her for going at a dangerous speed. & target collocation \\
\hline $\begin{array}{l}\text { She went on a religious tour, visiting all the churches } \\
\text { in the region. }\end{array}$ & target collocation \\
\hline $\begin{array}{l}\text { Can you recommend a suitable wine to have with fish? } \\
\text { It was only an old ball, but he was sorry to lose it. }\end{array}$ & $\begin{array}{l}\text { target collocation } \\
\text { control }\end{array}$ \\
\hline $\begin{array}{l}\text { The brain must get about five to six hours sleep a night } \\
\text { to work well. }\end{array}$ & control \\
\hline Lemon and honey is a very soothing drink if you have a cold. & control \\
\hline He owns a house by a farm. & control \\
\hline He pushed open the gate at the end of the path. & control \\
\hline There was a big lake where the children could swim. & control \\
\hline $\begin{array}{l}\text { They were impressed by the athlete's strong neck and } \\
\text { shoulders. }\end{array}$ & control \\
\hline The noise of the door opening downstairs woke her up. & control \\
\hline $\begin{array}{l}\text { The route between Birmingham and London was } \\
\text { closed for a week. }\end{array}$ & control \\
\hline She read the text carefully. & control \\
\hline
\end{tabular}

\section{Filler sentences}

She was very upset when her pet bird escaped from its cage.

Have you ever been a victim of crime?

Some people think that the sun orbits the earth.

Do you know the entry code for this door?

She kept a nail file in her handbag.

I don't like sitting at the front in the cinema.

He won a gold medal for running.

He had holes in his trouser pockets.

The judge sentenced him to two years in prison.

They put a limit on the number of people who could come.

They had a quick meal in an Italian restaurant.

After eating the sweets he had a red mouth.

Can you give me your phone number?

$\mathrm{He}$ ate an enormous plate of pasta.

The shops made a big profit in the sale.

They watched the ships coming into the harbour.

Can you send me that tape?

The video is about two hours long.

She always went for a long walk at the weekends.

We had a weekend's camping in a wood. 